\title{
ВРЕМЕННАЯ ДИНАМИКА ЦИТОКИНОВ В КРОВИ ПРИ ЭКСПЕРИМЕНТАЛЬНОМ АУТОИММУННОМ ЭНЦЕФАЛОМИЕЛИТЕ У КРЫС
}

\author{
Н. В. Позднякова ${ }^{1}$, В. И. Туробов², Е. Е. Гаранина ${ }^{3}$, О. А. Рябая ${ }^{1}$, Ю. К. Бирюкова ${ }^{4}$, Н. И. Минкевич², Е. В. Трубникова ${ }^{5}$, \\ А. Б. Шевелев ${ }^{6}$, Т. В. Кузнецова ${ }^{7}$ А. В. Белякова ${ }^{4}$, И. П. Удовиченко $2,8 凶$ \\ ${ }^{1}$ Национальный медицинский исследовательский центр онкологии имени Н. Н. Блохина, Москва \\ Филиал Института биоорганической химии имени академиков М. М. Шемякина и Ю. А. Овчинникова РАН, Пущино \\ ${ }^{3}$ Казанский (Приволжский) федеральный университет, Казань \\ ${ }^{4}$ Федеральный научный центр исследований и разработки иммунобиологических препаратов имени М. П. Чумакова РАН, Москва \\ ${ }^{5}$ Курский государственный университет, Курск \\ ${ }^{6}$ Институт биохимической физики имени Н. М. Эмануэля РАН, Москва \\ ${ }^{7}$ Институт общей генетики имени Н. И. Вавилова РАН, Москва \\ ${ }^{8}$ Пущинский государственный естественнонаучный институт, Пущино
}

\begin{abstract}
Изучена динамика содержания цитокинов у крыс линии Dark Agouti с индуцированным экспериментальным аутоиммунным энцефаломиелитом (ЭАЭ). В экспериментальную группу включили 11 животных, которым в подушечки задних лап инъецировали гомогенат спинного мозга беспородных крыс, смешанный с неполным адъювантом Фрейнда. В контрольную группу включили 7 животных, которым в подушечки задних лап вводили по 100 мкл фризиологического раствора, смешанного с неполным адъювантом Фрейнда. У животных ежедневно с 1 по 7 сутки отбирали по 500 мкл крови. Был выполнен мультиплексный цитокиновый тест с помощью набора реагентов Bio-Plex Pro Rat Cytokine 24-plex Assay на платформе Bio-Plex. Показано, что в контексте цитокинового профиля модель ЭАЭ у крыс отражает течение рассеянного склероза у человека в части динамики содержания системных лимфопролиферативных и гемопоэтических факторов: IL-1b, IL-2, IL-4, IL-5, IL-6 и IL-7. В части динамики факторов таксиса лимфоцитов, моноцитов и других клеток иммунной системы изученная модель удовлетворительно имитирует динамику содержания IL-17, RANTES (CCL-5) и MCP-1 (CCL-2), но отличается по динамике GRO/KC (CXCL1). В отношении фракторов, влияющих на цитотоксические и апоптотические реакции, сходство модели с заболеванием человека было выявлено по таким ключевым факторам, как IFN $\gamma$, IL-6 и IL-17, но не по TNF $\alpha$.
\end{abstract}

Ключевые слова: рассеянный склероз, экспериментальный аутоиммунный энцефаломиелит, миелин, иммунизация, мультиплексный цитокиновый тест

Благодарности: авторы благодарят Бориса Шевелева за участие в иммунизации животных.

Финансирование: исследование поддержано Министерством образования и науки Российской Федерации (Соглашение о предоставлении субсидии № 14.607.21.0133 от 27.10.2015, уникальный идентификатор RFMEFI60715X0133).

$\triangle$ Для корреспонденции: Удовиченко Игорь Петрович

Пр-т Науки, д. 6, г. Пущино, Московская обл., 142290; iudovichenko1@yandex.ru

Статья получена: 15.12.2017 Статья принята к печати: 20.12.2017

\section{TEMPORAL DYNAMICS OF CYTOKINES IN THE BLOOD OF RATS WITH EXPERIMENTALLY INDUCED AUTOIMMUNE ENCEPHALOMYELITIS}

Pozdniakova NV', Turobov VI², Garanina $\mathrm{EE}^{3}$, Ryabaya $\mathrm{OA}^{1}$, Biryukova YuK${ }^{4}$, Minkevich $\mathrm{Nl}^{2}$, Trubnikova $\mathrm{EV}^{5}$, Shevelev $\mathrm{AB}^{6}$, Kuznetsova TV7, Belyakova AV4, Udovichenko IP2,8凶

${ }^{1}$ Blokhin Russian Cancer Research Center, Moscow, Russia

${ }^{2}$ Shemyakin-Ovchinnikov Institute of Bioorganic Chemistry of the Russian Academy of Sciences, Pushchino branch

${ }^{3}$ Kazan Federal University, Kazan, Russia

${ }^{4}$ Chumakov Federal Center for Research and Development of Immunobiological Products, the Russian Academy of Sciences, Moscow, Russia

${ }^{5}$ Kursk State University, Kursk, Russia

${ }^{6}$ Emanuel Institute of Biochemical Physics of the Russian Academy of Sciences, Moscow, Russia

Vavilov Institute of General Genetics of the Russian Academy of Sciences, Moscow, Russia

${ }^{8}$ Pushchino State Institute of Natural Sciences, Pushchino, Russia

In this work we explore the temporal dynamics of cytokines in Dark Agouti rats with experimentally induced autoimmune encephalomyelitis (EAE). The main group consisted of 11 animals who were injected with $100 \mu \mathrm{l}$ (per leg) of spinal cord homogenate obtained from random-bred rats and combined with incomplete Freund's adjuvant to the hind footpads. The control group included 7 animals who received $100 \mu \mathrm{l}$ of normal saline mixed with incomplete Freund's adjuvant. Blood samples $(500 \mu \mathrm{l})$ were collected daily, starting from day 1 through day 7 . We ran a Bio-Plex-based multiplex cytokine assay on the samples using the Bio-Plex Pro Rat Cytokine 24-plex Assay kit. EAE in rats was shown to simulate progression of multiple sclerosis in humans in terms of temporal dynamics of lymphoproliferative and hematopoietic factors IL-1b, IL-2, IL-4, IL-5, IL-6, and IL-7. The studied model satisfactory imitates the dynamics of factors stimulating migration of lymphocytes, monocytes and other immune cells, including IL-17, RANTES (CCL-5) and MCP-1 (CCL-2) but excluding GRO/KC (CXCL1), which shows a different dynamics. The model also resembles patterns of human multiple sclerosis in terms of factors affecting cytotoxic and apoptotic reactions, including IFN $\gamma$, IL-6 and IL-17, but excluding TNF $\alpha$.

Keywords: multiple sclerosis, experimental autoimmune encephalomyelitis, myelin, immunization, multiplex cytokine assay

Acknowledgements: the authors thank Boris Shevelev for help in immunization of the animals.

Funding: this work was supported by the Ministry of Education and Science of the Russian Federation (Grant agreement 14.607.21.0133 dated October 27, 2015, ID RFMEFI60715X0133).

$\triangle$ Correspondence should be addressed: Igor Udovichenko

Pr-t Nauki, d. 6, Puschino, Moscow oblast, Russia, 142290; iudovichenko1@yandex.ru

Received: 15.12.2017 Accepted: 20.12.2017 
Рассеянный склероз (РС) представляет собой тяжелое нейродегенеративное заболевание аутоиммунной природы. Актуальность борьбы с ним обусловлена высокой частотой встречаемости, а также тяжестью течения, приводящей к частичной или полной потере подвижности. Большинство пациентов с РС полностью утрачивают подвижность через 25 лет после появления первых симптомов заболевания. Более половины пациентов с РС через 15 лет после начала болезни могут передвигаться только на костылях. До настоящего времени для лечения этой болезни не предложено эффективного этиотропного средства.

Заболевание возникает, как правило, у достаточно молодых людей: у 70-80 \% пациентов первые симптомы РС проявляются в возрасте от 20 до 40 лет [1]. Диагностика PC основана на клиническом осмотре невропатологом, магнитно-резонансном исследовании (МРТ) центральной нервной системы, гистологическом анализе материалов биопсии и аутопсии [2]. Болезнь имеет множество различающихся клинических проявлений, затрагивающих функции спинного и головного мозга, черепных нервов, мозжечка, когнитивные функции. При этом не выработано метода клинической диагностики, позволяющего однозначно оценивать тяжесть заболевания. Результаты МРТ, электроэнцефалографии и биохимического анализа пунктатов спинномозговой жидкости, хотя и являются ценными сведениями о состоянии больного, не всегда могут быть интерпретированы однозначно. Многие частные проявления РС могут быть вызваны не связанными с ним причинами: инфекционными заболеваниями, сосудистыми патологиями, аутоиммунными заболеваниями различной природы [3].

Выделяют четыре формы PC: возвратно-ремиттирующую (приступообразную), RRMS - 80-85 \% случаев; первичную прогрессирующую, PPMS - 10-15 \% случаев; возвратно-прогрессирующую, PRMS - 5 \% случаев; вторично-прогрессирующую, SPMS [4, 5]. Около половины пациентов с RRMS приобретают симптомы SPMS через 10 лет после начала заболевания. Свыше 90 \% пациентов с RRMS в конечном итоге приобретают симптоматику SPMS [6]

Основным патогностическим признаком РС является демиелинизация оболочек нейронов ЦНС, вызываемая скоплениями на их поверхности Т- и В-лимфоцитов. Для PC также характерно накопление олигоклональных антител в спинномозговой жидкости. Однако ответа на вопрос, где и как происходит первоначальный запуск клональной экспансии лимфоцитов, специфичных к основному белку миелина МВР, протекает ли этот процесс непосредственно в ЦНС при участии миелиновых оболочек или за пределами ЦНС с последующим накоплением в ней аутореактивных клеточных компонентов, нет [7].

Разработка средств лечения РС требует использования животных моделей, максимально точно воспроизводящих течение заболевания у человека. В качестве такой модели часто используют экспериментальный аутоиммунный энцефаломиелит (ЭАЭ) у мышей и крыс. Заболевание вызывают введением суспензии миелина или МВР в неполном адъюванте Фрейнда в подушечки лап [8]. В результате паралич задних конечностей инициируется через 1 мес. после иммунизации и длится в течение 4-6 мес. [9]. У крыс линии Dark Agouti (DA) ЭАЭ характеризуется существенно более быстрой динамикой. Паралич конечностей проявляется на 10-11 сутки и заканчивается на 14 сутки. Наиболее значимым отличием ЭАЭ у мышей от РС у человека является полное клиническое излечение иммунизи- рованных животных, недостижимое на сегодня для пациентов с РС.

В работе [10] приведены данные исследования цитокинового просиля у 19 пациентов с РС, в том числе у 16 с возвратно-ремиттирующей формой, у 1 - с первично-прогрессирующей и у 2 - с вторично-прогрессирующей формой, в зависимости от длительности заболевания: группа $1-4,2 \pm 0,8$ мес. и группа $2-76,6 \pm 14,3$ мес. с момента постановки первичного диагноза. В работе было показано, что на ранней стадии РС в сравнении с поздней стадией и данными для контрольной группы (люди без PC) в структуре цитокинов преобладают интерферон гамма (IFN $\gamma)$ и антивоспалительный лимфокин IL-10. На поздней стадии снижается содержание IL-1RA, IL-8, IL-12(p70), CCL-3, CCL-7, CCL-11, CXCL-10, FGF, IFN $\alpha$, а значительная представленность характерна для IL-1a, IL-1b, IL-2RA, IL-3, IL-4, IL-7, IL-12(p40), IL-18, CCL-5 (RANTES), CCL-27, HGF, MIF, M-CSF и TRAIL. Oсобое внимание авторы обратили на повышение содержания в крови больных PC IL-17, известного в качестве ключевого фактора развития псориатических повреждений кожи [11], а также IL-22 - у пациентов c RRMS. При анализе динамики цитокинов в спинномозговой жидкости пациентов авторы [10] пришли к выводу о ключевой роли накопления в ней IFN $\gamma$ и MIF (ключевоого фактора дегенарации суставной сумки при артрозе), а также факторов миграции лимфоцитов, индуцируемых ими: CCL-5 (RANTES), CCL-2 и CCL-27. Для спинномозговой жидкости, но не крови пациентов с РС оказалось характерным накопление проапоптотических факторов TNF- $\alpha$ и TRAIL.

Анализируя эти данные, можно сделать вывод о том, что для РС характерно длительное системное повышение активности факторов гемопоэза, особенно направленных на гранулоцитарный компонент, длительное поддержание Th1-ответа, избыток факторов миграции лимфоцитов и моноцитов при отсутствии выраженной провоспалительной реакции в виде факторов, стимулирующих продукцию и таксис нейтрофилов. Результаты исследования [10] важны для понимания динамики содержания различных цитокинов в крови и спинномозговой жидкости пациентов с РС, но в силу ограничений статистических методов значимость выявленных закономерностей остается под вопросом.

С учетом изложенного в рамках работы мы решали две задачи:

1) исследовать краткосрочную динамику цитокинов в модели ЭАЭ у крыс, для которой характерна высокая скорость патологического процесса;

2) сопоставить данные о содержании цитокинов при РС у человека и ЭАЭ у крыс с целью оценить пригодность этой модели для тестирования кандидатных средств для терапии PC.

\section{МАТЕРИАЛЫ И МЕТОДЫ}

\section{Индукция ЭАЭ у крыс}

Эксперименты на лабораторных животных были проведены в соответствии с «Правилами работ с использованием экспериментальных животных» (Приложение к приказу Министерства здравоохранения СССР от 12.08.1977 № 755) и с соблюдением принципов, изложенных в Хельсинкской декларации (2013).

Гомогенат спинного мозга беспородных крыс готовили по методике [12]. Далее использовали крыс линии Dark 
Agouti массой 220-250 г. В экспериментальную группу включили 11 животных, которым в день 0 вводили в подушечки каждой из двух задних лап заранее приготовленный гомогенат спинного мозга, смешанный с неполным адъювантом Фрейнда в пропорции $1:$ 1, общим объемом 100 мкл в каждую лапу. Животным контрольной группь $(n=7)$ вводили 100 мкл физиологического раствора, смешанного с неполным адъювантом Фрейнда также в пропорции 1: 1. С 1 по 7 сутки (за исключением 6-х суток) эксперимента у крыс ежедневно отбирали по 500 мкл крови из хвостовой вены. Из отобранной крови немедленно готовили сыворотку по следующей методике: кровь помещали в вакуумные пробирки Vacuette $Z$ serum sepclot activator (для сыворотки) и центрифугировали в течение 15-20 мин при 2500 об./мин и температуре $+4^{\circ} \mathrm{C}$. Сыворотку (около 100 мкл) переносили в микроцентрифужные пробирки и замораживали при $-20{ }^{\circ} \mathrm{C}$. Крыс ежедневно взвешивали и фиксировали в баллах индекс тяжести клинических проявлений ЭАЭ по следующей шкале: 0 - нет симптомов, 1 - снижение тонуса хвоста, 2 - нарушение установочного рефлекса, 3 - частичный паралич, 4 - полный паралич, 5 - животные погибли или умирают. В сомнительных случаях индекс фиксировали с занижением. Явные признаки ЭАЭ у животных контрольной группы фриксировали с 8 по 14 день с начала эксперимента. Пик заболевания длился 2-3 дня и приходился на 11-14 сутки с начала эксперимента.

\section{Мультиплексный цитокиновый тест}

Анализ выполнялся на платформе Bio-Plex (Bio-Rad, CША) с помощью набора реагентов Bio-Plex Pro Rat Cytokine 24-plex Assay (Bio-Rad), работа которого основана на использовании магнитных частиц с нанесенными моноклональными антителами к цитокинам крысы, согласно инструкции производителя и в соответствии с ранее опубликованным протоколом [13]. Для анализа использовали аликвоты сыворотки объемом 50 мкл. Среднюю интенсивность флуоресценции каждого образца определяли на приборе Luminex 200 analyzer (Luminex Corporation, США). Для сбора данных использовали программное обеспечение MasterPlex CT и MasterPlex QT analysis software (Hitachi Solutions America, США). Для каждого аналита строили калибровочный график с использованием 7 концентраций, выражая ее в пг/мл сыворотки.

\section{Статистическая обработка данных}

Для экспериментальной и контрольной групп для каждого цитокина на каждые сутки эксперимента вычисляли медианное значение содержания для группы и два квартильных значения. После этого проводили сопоставление достоверности различий между группами с помощью непараметрического критерия Манна-Уитни, используя пакет программ Statistica 8.0 для Windows. При p-value > 0,05 различия были недостоверны; также использовали три порога достоверности: первый $-\leq 0,05$; второй $-\leq 0,01$; третий $-\leq 0,001$.

\section{РЕЗУЛЬТАТЫ ИССЛЕДОВАНИЯ}

В настоящее время сведений о краткосрочной динамике цитокинов в крови человека и лабораторных животных все еще недостаточно, т. к. мультиплексные тесты дороги, а ежедневный отбор крови у больных и животных сопря- жен с техническими и этическими трудностями. Анализ динамики содержания цитокинов в контрольной группе показал, что введение неполного адъюванта Фрейнда в подушечки лап само по себе является фактором, вызывающим значительные волнообразные колебания уровня цитокинов в крови, хотя и не приводит к развитию ЭАЭ. Это обстоятельство снижает достоверность оценки влияния гомогената спинного мозга на развитие экспериментального заболевания и требует использования статистических методов анализа динамики содержания цитокинов.

У всех животных экспериментальной группы наблюдали паралич задних конечностей. Восходящая фраза заболевания пришлась на 11-13 сутки, нисходящая - на 12-17 сутки. К 18 суткам симптомы паралича у всех животных полностью исчезали. Таким образом, отбор крови, который производили в 1-7 сутки, осуществляли на стадии, когда внешние проявления ЭАЭ отсутствовали.

Анализ данных (табл. 1 и 2), показал, что в первые сутки эксперимента содержание 13 из 24 анализируемых цитокинов - IL-1a, IL-2, IL-4, IL-5, IL-6, IL-7, IL-12(p70), IL-17, IL-18, G-CSF, IFN- $\gamma$, RANTES (CCL-5) и MCP-1 (CCL-2) - в экспериментальной группе было существенно выше, чем в контрольной, (например, до 220 \% - для IL-4) по второму и третьему порогам достоверности (рис. 1). Во вторые сутки ни по одному цитокину достоверных различий не наблюдали. На третьи сутки были выявлены различия для

Таблица 1. Оценка достоверности различий между экспериментальной и контрольной группами животных с помощью непараметрического критерия Манна-Уитни с поправкой Йейста на непрерывность. Результат проверки гипотезы об отсутствии значимых различий между выборками выражен виде критерия Фишера (р). При р > 0,05 различия были недостоверны; также использовали 3 порога достоверности: первый $-\leq 0,05$; второй $\leq 0,01$; третий $-\leq 0,001$ (в таблице обозначены цифрами 1, 2 и 3 соответственно)

\begin{tabular}{|l|c|c|c|c|c|c|}
\hline \multirow{2}{*}{\multicolumn{1}{|c|}{ Цитокин }} & \multicolumn{7}{|c|}{ Сутки эксперимента } \\
\cline { 2 - 7 } & 1 & 2 & 3 & 4 & 5 & 7 \\
\hline IL-1a & 3 & - & - & - & 2 & 2 \\
\hline IL-1b & - & - & 1 & - & 2 & - \\
\hline IL-2 & 2 & - & - & - & - & 1 \\
\hline IL-4 & 3 & - & - & - & - & 2 \\
\hline IL-5 & 2 & - & - & - & - & 2 \\
\hline IL-6 & 3 & - & - & - & - & 1 \\
\hline IL-7 & 2 & - & - & - & - & 2 \\
\hline IL-10 & - & - & - & - & - & 2 \\
\hline IL-12 & 2 & - & - & - & - & - \\
\hline IL-13 & - & - & - & - & 2 & - \\
\hline IL-17 & 3 & - & - & - & - & 2 \\
\hline IL-18 & 3 & - & - & - & - & 2 \\
\hline Эритропоэтин EPO & - & - & - & - & 1 & 2 \\
\hline G-CSF & 3 & - & - & - & - & - \\
\hline GM-CSF & - & - & - & - & - & 3 \\
\hline GRO/KC & - & - & - & - & - & - \\
\hline IFN- $\gamma$ & 2 & - & - & - & - & 1 \\
\hline M-CSF & - & - & - & - & - & - \\
\hline MIP-3a & - & - & - & - & - & - \\
\hline RANTES & 2 & - & - & - & - & 2 \\
\hline TNF $\alpha$ & - & - & - & - & - & - \\
\hline VEGF & - & - & 1 & - & - & - \\
\hline Лептин & - & - & - & - & - & - \\
\hline MCP-1 & 2 & - & - & - & - & 2 \\
\hline
\end{tabular}


Таблица 2. Описательная статистика изменения содержания цитокинов в экспериментальной и контрольной группах крыс с экспериментальным аутоиммунным энцесраломиелитом

\begin{tabular}{|c|c|c|c|c|c|c|c|c|c|c|c|c|c|}
\hline \multirow{3}{*}{ Цитокин } & \multicolumn{13}{|c|}{ Сутки эксперимента } \\
\hline & \multirow{2}{*}{$\begin{array}{l}\text { Пара- } \\
\text { метр }\end{array}$} & \multicolumn{2}{|l|}{1} & \multicolumn{2}{|l|}{2} & \multicolumn{2}{|l|}{3} & \multicolumn{2}{|l|}{4} & \multicolumn{2}{|l|}{5} & \multicolumn{2}{|l|}{7} \\
\hline & & Контроль & Опыт & Контроль & Опыт & Контроль & Опыт & Контроль & Опыт & Контроль & Опыт & Контроль & Опыт \\
\hline \multirow{6}{*}{ IL-1a } & Среднее & 195 & 387 & 182 & 206 & 268 & 181 & 193 & 144 & 319 & 138 & 203 & 359 \\
\hline & $\mathrm{N}$ & 6 & 10 & 8 & 12 & 6 & 11 & 7 & 11 & 7 & 11 & 7 & 11 \\
\hline & Ст. откл. & 87 & 92 & 65 & 61 & 148 & 122 & 113 & 76 & 279 & 75 & 84 & 134 \\
\hline & Q25 & 132 & 304 & 133 & 170 & 160 & 68 & 98 & 83 & 182 & 90 & 139 & 218 \\
\hline & Медиана & 188 & 347 & 175 & 204 & 218 & 200 & 195 & 155 & 184 & 121 & 184 & 411 \\
\hline & Q75 & 288 & 487 & 226 & 264 & 396 & 237 & 274 & 210 & 396 & 187 & 269 & 462 \\
\hline \multirow{6}{*}{ IL-1b } & Среднее & 433 & 401 & 412 & 274 & 1033 & 493 & 469 & 265 & 819 & 250 & 319 & 571 \\
\hline & $\mathrm{N}$ & 6 & 10 & 8 & 12 & 6 & 11 & 7 & 11 & 7 & 11 & 7 & 11 \\
\hline & Ст. откл. & 386 & 382 & 244 & 184 & 427 & 362 & 432 & 157 & 861 & 164 & 180 & 288 \\
\hline & Q25 & 251 & 236 & 211 & 148 & 701 & 134 & 119 & 101 & 279 & 151 & 180 & 300 \\
\hline & Медиана & 315 & 270 & 399 & 222 & 967 & 441 & 412 & 310 & 607 & 214 & 204 & 536 \\
\hline & Q75 & 411 & 367 & 550 & 370 & 1477 & 782 & 553 & 409 & 730 & 307 & 504 & 821 \\
\hline \multirow{6}{*}{ IL-2 } & Среднее & 356 & 607 & 366 & 436 & 367 & 500 & 472 & 414 & 579 & 373 & 744 & 1092 \\
\hline & $\mathrm{N}$ & 6 & 10 & 8 & 12 & 6 & 11 & 7 & 11 & 7 & 11 & 7 & 11 \\
\hline & Ст. откл. & 103 & 138 & 127 & 207 & 209 & 303 & 292 & 180 & 286 & 215 & 245 & 348 \\
\hline & Q25 & 278 & 579 & 285 & 319 & 186 & 311 & 213 & 260 & 396 & 205 & 543 & 776 \\
\hline & Медиана & 374 & 597 & 345 & 331 & 332 & 432 & 308 & 362 & 557 & 284 & 657 & 1145 \\
\hline & Q75 & 443 & 626 & 463 & 629 & 523 & 608 & 762 & 647 & 668 & 509 & 914 & 1368 \\
\hline \multirow{6}{*}{ IL-4 } & Среднее & 11 & 36 & 9 & 19 & 9 & 24 & 14 & 18 & 19 & 16 & 41 & 90 \\
\hline & $\mathrm{N}$ & 6 & 10 & 8 & 12 & 6 & 11 & 7 & 11 & 7 & 11 & 7 & 11 \\
\hline & Ст. откл. & 6 & 16 & 4 & 19 & 8 & 23 & 12 & 16 & 13 & 15 & 27 & 40 \\
\hline & Q25 & 6 & 27 & 5 & 5 & 4 & 4 & 4 & 5 & 9 & 4 & 17 & 57 \\
\hline & Медиана & 11 & 30 & 8 & 8 & 6 & 17 & 8 & 12 & 15 & 14 & 33 & 76 \\
\hline & Q75 & 17 & 38 & 12 & 37 & 10 & 32 & 29 & 34 & 33 & 23 & 64 & 128 \\
\hline \multirow{6}{*}{ IL-5 } & Среднее & 77 & 128 & 59 & 69 & 56 & 88 & 69 & 74 & 91 & 68 & 136 & 193 \\
\hline & $\mathrm{N}$ & 6 & 10 & 8 & 12 & 6 & 11 & 7 & 11 & 7 & 11 & 7 & 11 \\
\hline & Ст. откл. & 25 & 27 & 33 & 51 & 47 & 59 & 62 & 45 & 43 & 49 & 46 & 34 \\
\hline & Q25 & 55 & 110 & 26 & 22 & 23 & 26 & 22 & 20 & 43 & 22 & 106 & 174 \\
\hline & Медиана & 78 & 123 & 63 & 54 & 30 & 83 & 23 & 67 & 88 & 83 & 130 & 193 \\
\hline & Q75 & 97 & 147 & 78 & 121 & 113 & 133 & 144 & 106 & 118 & 106 & 176 & 212 \\
\hline \multirow{6}{*}{ IL-6 } & Среднее & 232 & 503 & 351 & 273 & 468 & 1595 & 515 & 540 & 600 & 316 & 668 & 1145 \\
\hline & $\mathrm{N}$ & 6 & 10 & 8 & 12 & 6 & 11 & 7 & 11 & 7 & 11 & 7 & 11 \\
\hline & Ст. откл. & 79 & 204 & 226 & 255 & 404 & 3960 & 572 & 743 & 284 & 269 & 292 & 496 \\
\hline & Q25 & 172 & 379 & 169 & 63 & 170 & 96 & 76 & 85 & 414 & 46 & 456 & 640 \\
\hline & Медиана & 224 & 444 & 340 & 182 & 349 & 428 & 190 & 240 & 584 & 261 & 521 & 1240 \\
\hline & Q75 & 287 & 463 & 540 & 470 & 758 & 635 & 1132 & 559 & 713 & 556 & 877 & 1624 \\
\hline \multirow{6}{*}{ IL-7 } & Среднее & 103 & 254 & 68 & 123 & 70 & 178 & 111 & 114 & 125 & 106 & 228 & 612 \\
\hline & $\mathrm{N}$ & 6 & 10 & 8 & 12 & 6 & 11 & 7 & 11 & 7 & 11 & 7 & 11 \\
\hline & Ст. откл. & 50 & 96 & 62 & 128 & 83 & 169 & 129 & 115 & 77 & 98 & 146 & 236 \\
\hline & Q25 & 58 & 181 & 14 & 16 & 12 & 13 & 11 & 16 & 50 & 10 & 119 & 428 \\
\hline & Медиана & 102 & 226 & 63 & 72 & 23 & 144 & 20 & 64 & 109 & 108 & 161 & 724 \\
\hline & Q75 & 145 & 350 & 90 & 246 & 159 & 281 & 239 & 224 & 209 & 165 & 391 & 787 \\
\hline \multirow{6}{*}{ IL-10 } & Среднее & 149 & 240 & 105 & 180 & 121 & 215 & 163 & 157 & 208 & 132 & 403 & 634 \\
\hline & $\mathrm{N}$ & 6 & 10 & 8 & 12 & 6 & 11 & 7 & 11 & 7 & 11 & 7 & 11 \\
\hline & Ст. откл. & 70 & 80 & 53 & 131 & 93 & 200 & 129 & 99 & 70 & 106 & 160 & 226 \\
\hline & Q25 & 91 & 208 & 61 & 57 & 56 & 63 & 56 & 58 & 144 & 44 & 254 & 420 \\
\hline & Медиана & 142 & 220 & 101 & 183 & 67 & 149 & 88 & 116 & 214 & 116 & 413 & 557 \\
\hline & Q75 & 217 & 280 & 129 & 284 & 237 & 277 & 294 & 272 & 287 & 208 & 550 & 821 \\
\hline
\end{tabular}


Продолжение табл. 2

\begin{tabular}{|c|c|c|c|c|c|c|c|c|c|c|c|c|c|}
\hline \multirow{6}{*}{ IL-12 } & Среднее & 46 & 125 & 35 & 56 & 43 & 81 & 58 & 54 & 68 & 47 & 155 & 288 \\
\hline & $\mathrm{N}$ & 6 & 10 & 8 & 12 & 6 & 11 & 7 & 11 & 7 & 11 & 7 & 11 \\
\hline & Ст. откл. & 29 & 62 & 35 & 61 & 56 & 102 & 68 & 61 & 50 & 59 & 98 & 143 \\
\hline & Q25 & 16 & 88 & 5 & 6 & 5 & 6 & 6 & 6 & 15 & 4 & 81 & 173 \\
\hline & Медиана & 49 & 99 & 32 & 23 & 10 & 53 & 12 & 29 & 59 & 26 & 125 & 277 \\
\hline & Q75 & 74 & 133 & 46 & 123 & 98 & 118 & 135 & 70 & 104 & 81 & 212 & 425 \\
\hline \multirow{6}{*}{ IL-13 } & Среднее & 31 & 32 & 15 & 16 & 20 & 22 & 22 & 13 & 19 & 13 & 33 & 61 \\
\hline & $\mathrm{N}$ & 6 & 10 & 8 & 12 & 6 & 11 & 7 & 11 & 7 & 11 & 7 & 11 \\
\hline & Ст. откл. & 28 & 31 & 8 & 15 & 8 & 20 & 26 & 11 & 6 & 8 & 21 & 37 \\
\hline & Q25 & 18 & 16 & 9 & 6 & 13 & 9 & 7 & 6 & 15 & 6 & 19 & 29 \\
\hline & Медиана & 21 & 20 & 14 & 9 & 20 & 13 & 13 & 9 & 18 & 11 & 23 & 44 \\
\hline & Q75 & 28 & 37 & 22 & 20 & 23 & 28 & 26 & 15 & 22 & 17 & 58 & 95 \\
\hline \multirow{6}{*}{ IL-17 } & Среднее & 24 & 55 & 17 & 25 & 19 & 36 & 26 & 27 & 36 & 25 & 67 & 119 \\
\hline & $\mathrm{N}$ & 6 & 10 & 8 & 12 & 6 & 11 & 7 & 11 & 7 & 11 & 7 & 11 \\
\hline & Ст. откл. & 12 & 20 & 15 & 28 & 24 & 36 & 32 & 23 & 22 & 24 & 38 & 43 \\
\hline & Q25 & 12 & 43 & 3 & 3 & 3 & 3 & 3 & 4 & 16 & 3 & 38 & 84 \\
\hline & Медиана & 24 & 49 & 16 & 15 & 4 & 34 & 5 & 21 & 35 & 28 & 62 & 108 \\
\hline & Q75 & 37 & 56 & 24 & 44 & 50 & 52 & 52 & 42 & 58 & 45 & 102 & 168 \\
\hline \multirow{6}{*}{ IL-18 } & Среднее & 1110 & 2360 & 909 & 1480 & 976 & 2004 & 1351 & 1829 & 1628 & 1562 & 2476 & 4182 \\
\hline & $\mathrm{N}$ & 6 & 10 & 8 & 12 & 6 & 11 & 7 & 11 & 7 & 11 & 7 & 11 \\
\hline & Ст. откл. & 340 & 822 & 345 & 828 & 600 & 1513 & 895 & 1390 & 455 & 1557 & 774 & 1495 \\
\hline & Q25 & 846 & 1671 & 623 & 707 & 591 & 582 & 615 & 779 & 1494 & 426 & 1663 & 3219 \\
\hline & Медиана & 1009 & 2167 & 877 & 1444 & 609 & 1677 & 1064 & 1157 & 1616 & 1152 & 2334 & 3808 \\
\hline & Q75 & 1462 & 2766 & 1094 & 2243 & 1701 & 3435 & 2055 & 2367 & 1831 & 2632 & 3217 & 4100 \\
\hline \multirow{6}{*}{$\begin{array}{l}\text { Эритропоэ- } \\
\text { тин ЕРО }\end{array}$} & Среднее & 202 & 263 & 186 & 242 & 197 & 310 & 238 & 246 & 281 & 175 & 342 & 745 \\
\hline & $\mathrm{N}$ & 6 & 10 & 8 & 12 & 6 & 11 & 7 & 11 & 7 & 11 & 7 & 11 \\
\hline & Ст. откл. & 68 & 60 & 77 & 141 & 62 & 240 & 71 & 95 & 86 & 91 & 117 & 345 \\
\hline & Q25 & 154 & 235 & 127 & 110 & 158 & 127 & 173 & 153 & 209 & 107 & 249 & 504 \\
\hline & Медиана & 175 & 258 & 179 & 219 & 202 & 272 & 209 & 223 & 247 & 166 & 360 & 585 \\
\hline & Q75 & 235 & 287 & 225 & 346 & 241 & 352 & 300 & 346 & 373 & 197 & 415 & 1060 \\
\hline \multirow{6}{*}{ G-CSF } & Среднее & 3 & 6 & 3 & 4 & 3 & 6 & 4 & 4 & 5 & 4 & 9 & 15 \\
\hline & $\mathrm{N}$ & 6 & 10 & 8 & 12 & 6 & 11 & 7 & 11 & 7 & 11 & 7 & 11 \\
\hline & Ст. откл. & 1 & 3 & 1 & 3 & 2 & 6 & 3 & 2 & 1 & 2 & 6 & 9 \\
\hline & Q25 & 3 & 4 & 2 & 2 & 2 & 2 & 2 & 2 & 3 & 2 & 4 & 8 \\
\hline & Медиана & 3 & 6 & 3 & 3 & 2 & 4 & 2 & 3 & 4 & 3 & 6 & 12 \\
\hline & Q75 & 4 & 7 & 3 & 6 & 5 & 8 & 6 & 5 & 6 & 5 & 14 & 24 \\
\hline \multirow{6}{*}{ GM-CSF } & Среднее & 5 & 7 & 5 & 5 & 6 & 9 & 8 & 5 & 6 & 4 & 8 & 2 \\
\hline & $\mathrm{N}$ & 6 & 10 & 8 & 12 & 6 & 11 & 7 & 11 & 7 & 11 & 7 & 11 \\
\hline & Ст. откл. & 3 & 3 & 3 & 3 & 4 & 10 & 6 & 2 & 4 & 2 & 2 & 1 \\
\hline & Q25 & 2 & 6 & 3 & 2 & 3 & 4 & 4 & 3 & 2 & 2 & 7 & 1 \\
\hline & Медиана & 5 & 7 & 6 & 5 & 6 & 9 & 9 & 5 & 5 & 5 & 8 & 2 \\
\hline & Q75 & 6 & 10 & 8 & 8 & 9 & 10 & 10 & 7 & 11 & 5 & 10 & 3 \\
\hline \multirow{6}{*}{ GRO/KC } & Среднее & 161 & 237 & 156 & 165 & 217 & 153 & 201 & 90 & 153 & 116 & 163 & 178 \\
\hline & $\mathrm{N}$ & 6 & 10 & 8 & 12 & 6 & 11 & 7 & 11 & 7 & 11 & 7 & 11 \\
\hline & Ст. откл. & 93 & 104 & 79 & 65 & 134 & 97 & 115 & 31 & 128 & 43 & 62 & 57 \\
\hline & Q25 & 72 & 124 & 101 & 135 & 75 & 64 & 84 & 62 & 82 & 74 & 103 & 153 \\
\hline & Медиана & 142 & 267 & 140 & 157 & 239 & 133 & 198 & 96 & 90 & 119 & 155 & 170 \\
\hline & Q75 & 270 & 331 & 191 & 189 & 341 & 272 & 299 & 116 & 324 & 145 & 184 & 222 \\
\hline \multirow{6}{*}{$\mathrm{IFN} \gamma$} & Среднее & 36 & 79 & 30 & 42 & 32 & 63 & 61 & 45 & 53 & 40 & 107 & 215 \\
\hline & $\mathrm{N}$ & 6 & 10 & 8 & 12 & 6 & 11 & 7 & 11 & 7 & 11 & 7 & 11 \\
\hline & Ст. откл. & 14 & 46 & 13 & 40 & 23 & 77 & 62 & 41 & 19 & 35 & 45 & 122 \\
\hline & Q25 & 27 & 52 & 20 & 14 & 17 & 14 & 17 & 15 & 36 & 12 & 65 & 87 \\
\hline & Медиана & 30 & 64 & 27 & 20 & 20 & 43 & 24 & 28 & 52 & 27 & 98 & 206 \\
\hline & Q75 & 46 & 74 & 41 & 60 & 56 & 64 & 95 & 66 & 76 & 69 & 148 & 290 \\
\hline
\end{tabular}


Продолжение табл. 2

\begin{tabular}{|c|c|c|c|c|c|c|c|c|c|c|c|c|c|}
\hline \multirow{6}{*}{ M-CSF } & Среднее & 132 & 174 & 92 & 89 & 91 & 121 & 100 & 79 & 93 & 104 & 113 & 164 \\
\hline & $\mathrm{N}$ & 6 & 10 & 8 & 12 & 6 & 11 & 7 & 11 & 7 & 11 & 7 & 11 \\
\hline & Ст. откл. & 42 & 44 & 46 & 38 & 70 & 83 & 116 & 49 & 54 & 60 & 55 & 74 \\
\hline & Q25 & 99 & 143 & 64 & 55 & 32 & 53 & 32 & 33 & 39 & 41 & 52 & 110 \\
\hline & Медиана & 124 & 159 & 80 & 88 & 71 & 106 & 40 & 69 & 69 & 105 & 141 & 149 \\
\hline & Q75 & 175 & 205 & 122 & 111 & 174 & 183 & 164 & 121 & 147 & 164 & 165 & 234 \\
\hline \multirow{6}{*}{ MIP-3a } & Среднее & 70 & 88 & 55 & 49 & 45 & 88 & 69 & 64 & 76 & 45 & 88 & 128 \\
\hline & $\mathrm{N}$ & 6 & 10 & 8 & 12 & 6 & 11 & 7 & 11 & 7 & 11 & 7 & 11 \\
\hline & Ст. откл. & 19 & 38 & 44 & 40 & 44 & 95 & 80 & 59 & 45 & 40 & 36 & 44 \\
\hline & Q25 & 52 & 47 & 19 & 13 & 12 & 21 & 14 & 13 & 25 & 11 & 65 & 107 \\
\hline & Медиана & 76 & 94 & 41 & 31 & 21 & 53 & 19 & 51 & 91 & 34 & 83 & 139 \\
\hline & Q75 & 86 & 122 & 85 & 83 & 99 & 134 & 161 & 83 & 122 & 90 & 102 & 171 \\
\hline \multirow{6}{*}{ RANTES } & Среднее & 685 & 1070 & 342 & 470 & 295 & 696 & 364 & 505 & 574 & 456 & 757 & 1311 \\
\hline & $\mathrm{N}$ & 6 & 10 & 8 & 12 & 6 & 11 & 7 & 11 & 7 & 11 & 7 & 11 \\
\hline & Ст. откл. & 230 & 247 & 277 & 422 & 306 & 541 & 403 & 381 & 208 & 389 & 147 & 388 \\
\hline & Q25 & 545 & 966 & 80 & 73 & 108 & 60 & 37 & 51 & 437 & 39 & 726 & 814 \\
\hline & Медиана & 665 & 1052 & 334 & 387 & 139 & 679 & 57 & 545 & 634 & 660 & 758 & 1495 \\
\hline & Q75 & 805 & 1129 & 558 & 855 & 481 & 1212 & 821 & 777 & 687 & 735 & 846 & 1580 \\
\hline \multirow{6}{*}{ TNF $\alpha$} & Среднее & 58 & 39 & 25 & 30 & 29 & 33 & 30 & 28 & 33 & 27 & 54 & 82 \\
\hline & $\mathrm{N}$ & 6 & 10 & 8 & 12 & 6 & 11 & 7 & 11 & 7 & 11 & 7 & 11 \\
\hline & Ст. откл. & 26 & 10 & 15 & 18 & 18 & 19 & 20 & 14 & 11 & 19 & 26 & 42 \\
\hline & Q25 & 42 & 29 & 17 & 16 & 16 & 16 & 17 & 16 & 21 & 14 & 32 & 51 \\
\hline & Медиана & 57 & 39 & 19 & 21 & 19 & 27 & 23 & 25 & 36 & 24 & 57 & 72 \\
\hline & Q75 & 72 & 49 & 26 & 47 & 46 & 44 & 49 & 34 & 39 & 29 & 82 & 106 \\
\hline \multirow{6}{*}{ VEGF } & Среднее & 130 & 87 & 88 & 55 & 128 & 73 & 107 & 46 & 133 & 65 & 92 & 110 \\
\hline & $\mathrm{N}$ & 6 & 10 & 8 & 12 & 6 & 11 & 7 & 11 & 7 & 11 & 7 & 11 \\
\hline & Ст. откл. & 110 & 90 & 57 & 79 & 73 & 80 & 78 & 24 & 149 & 49 & 44 & 50 \\
\hline & Q25 & 41 & 52 & 42 & 20 & 53 & 37 & 54 & 32 & 33 & 29 & 57 & 57 \\
\hline & Медиана & 119 & 60 & 88 & 35 & 129 & 44 & 78 & 36 & 97 & 46 & 84 & 100 \\
\hline & Q75 & 132 & 74 & 128 & 44 & 178 & 84 & 185 & 58 & 136 & 89 & 146 & 139 \\
\hline \multirow{6}{*}{ Лептин } & Среднее & 158 & 217 & 59 & 131 & 121 & 264 & 129 & 90 & 231 & 213 & 239 & 460 \\
\hline & $\mathrm{N}$ & 6 & 10 & 8 & 12 & 6 & 11 & 7 & 11 & 7 & 11 & 7 & 11 \\
\hline & Ст. откл. & 161 & 240 & 77 & 184 & 163 & 255 & 202 & 167 & 219 & 199 & 237 & 358 \\
\hline & Q25 & 10 & 1 & 20 & 11 & 11 & 16 & 3 & 4 & 12 & 17 & 0 & 20 \\
\hline & Медиана & 150 & 137 & 24 & 27 & 21 & 312 & 21 & 20 & 246 & 286 & 324 & 620 \\
\hline & Q75 & 301 & 437 & 83 & 273 & 304 & 482 & 375 & 30 & 447 & 419 & 404 & 745 \\
\hline \multirow{6}{*}{ MCP-1 } & Среднее & 1979 & 2662 & 2277 & 2317 & 2428 & 3097 & 2071 & 2468 & 2117 & 2254 & 1910 & 3300 \\
\hline & $\mathrm{N}$ & 6 & 10 & 8 & 12 & 6 & 11 & 7 & 11 & 7 & 11 & 7 & 11 \\
\hline & Ст. откл. & 413 & 365 & 949 & 754 & 576 & 1120 & 830 & 1141 & 830 & 623 & 557 & 879 \\
\hline & Q25 & 1592 & 2353 & 1606 & 1729 & 2130 & 2126 & 1501 & 1575 & 1651 & 1889 & 1340 & 2986 \\
\hline & Медиана & 2102 & 2606 & 2155 & 2063 & 2428 & 3108 & 1849 & 2192 & 2012 & 2448 & 1946 & 3411 \\
\hline & Q75 & 2317 & 2864 & 2909 & 3047 & 2904 & 3762 & 2369 & 3021 & 2189 & 2750 & 2405 & 3846 \\
\hline
\end{tabular}

IL-1b и VEGF $(\leq 0,05)$, но на четвертые сутки вновь ни для одного цитокина достоверных различий не было. На пятые сутки эксперимента в экспериментальной группе достоверно снизилось содержание IL-1a, IL-1b, IL-13 и эритропоэтина (рис. 2).

На седьмые сутки различия между группами были выявлены по 14 цитокинам из 24 исследованных. Это были практически все те же цитокины, различия по которым наблюдали в первые сутки эксперимента, с тем отличием что были зафиксированы статистически значимые изменения по IL-10 и эритропоэтину GM-CSF и не были зафиксированы - по IL-12(p70) и G-CSF (рис. 3). Необходимо отметить, что содержание 13 из 14 цитокинов в экспери- ментальной группе оказалось выше, чем в контрольной. Исключение составил только GM-CSF, содержание которого снизилось с 8,17 пг/мл до 2,00 пг/мл.

\section{ОБСУЖДЕНИЕ РЕЗУЛЬТАТОВ}

Резкий рост содержания различных цитокинов в первые сутки эксперимента с последующим падением во вторые сутки следует интерпретировать как острый клональнонеспецифичный ответ на появление избытка миелина вне ЦНС. Вероятно, реакция на миелин в виде одновременного выброса нескольких лимфопролиферативных факторов стимулируется гиперпродукцией IL-1b, источником 


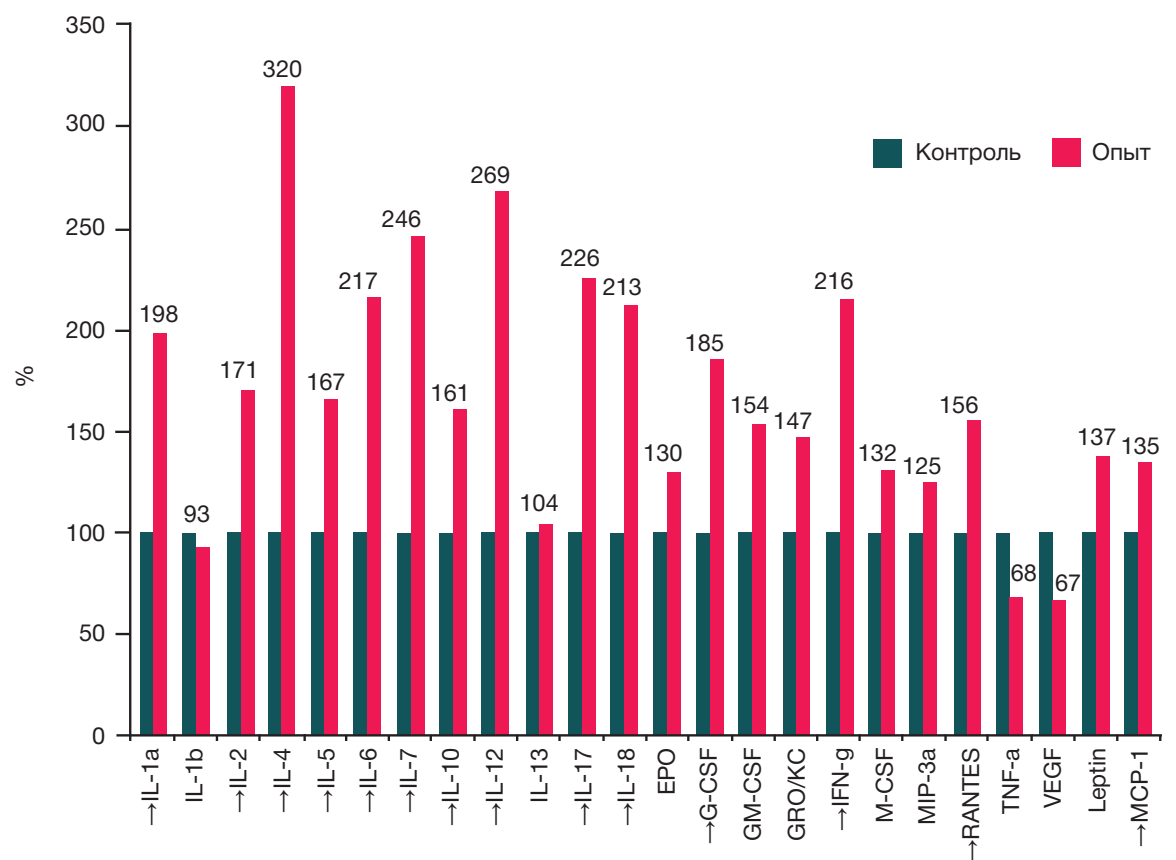

Рис. 1. Изменение содержания цитокинов в сыворотке крови крыс экспериментальной группы по сравнению с крысами контрольной группы через 1 сутки после иммунизации. Содержание цитокинов в крови животных контрольной группы были приняты за 100 \%. Достоверные различия показаны стрелками

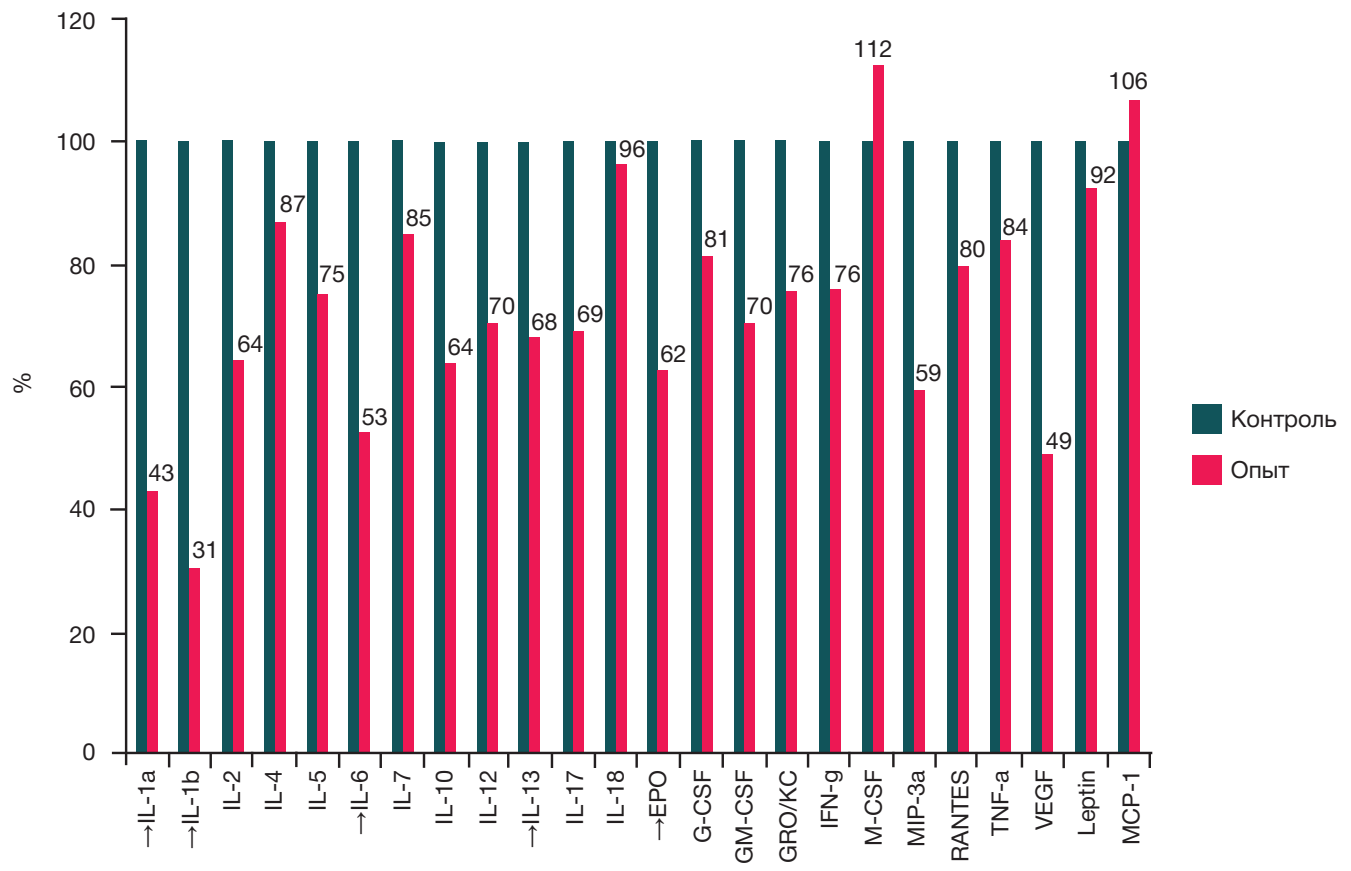

Рис. 2. Изменение содержания цитокинов в сыворотке крови крыс экспериментальной группы по сравнению с крысами контрольной группы через 5 суток после иммунизации. Содержание цитокинов в крови животных контрольной группы были приняты за 100 \%. Достоверные различия показаны стрелками

которого являются макрофаги, дендритные клетки или фибробласты кожи.

Рост уровня продукции цитокинов на пятые и особенно седьмые сутки эксперимента, скорее всего, можно объяснить накоплением в организме животных клонально-специфичных лимфоцитов различных типов, среди которых могут быть лимфоциты с аутологичной реактивностью в отношении миелина. Для системной клональной экспансии Т-лимфоцитов характерна именно такая длительность реакции, после чего возникают внешние проявления физиологической реакции.

Наиболее значимые в абсолютном выражении различия между экспериментальной и контрольной группами на седьмые сутки эксперимента были выявлены для IL-18 2475,85/4182,05 пг/мл, RANTES - 756,78/1310,78 пг/мл,
MCP-1 (CCL-2) - 1909,68/3300,50 пг/мл и IL-2 743,52/1091,57 пг/мл. С учетом того, что для IL-2 доказана способность индуцировать продукцию многих других ростовых и гемопоэтических факторов [14], можно предположить, что именно этот лимфокин является индуктором таких неспецисических для иммунной системы факторов, как VEGF и эритропоэтин, а также IL-13, всплеск продукции которых запаздывал по фазе относительно IL-2. C учетом длительной персистенции высоких уровней продукции IL-2, по данным [10], характерной для пациентов с PC, можно предположить главную роль этого лимфокина в характерной для РС массовой пролиферации лимфоцитов за пределами ЦНС. Повышение уровня продукции IL-4, IL-5, IL-6, IL-7 и IL-13, также представляющих собой лимфопролиферативные и гепомоэтические факторы, на 


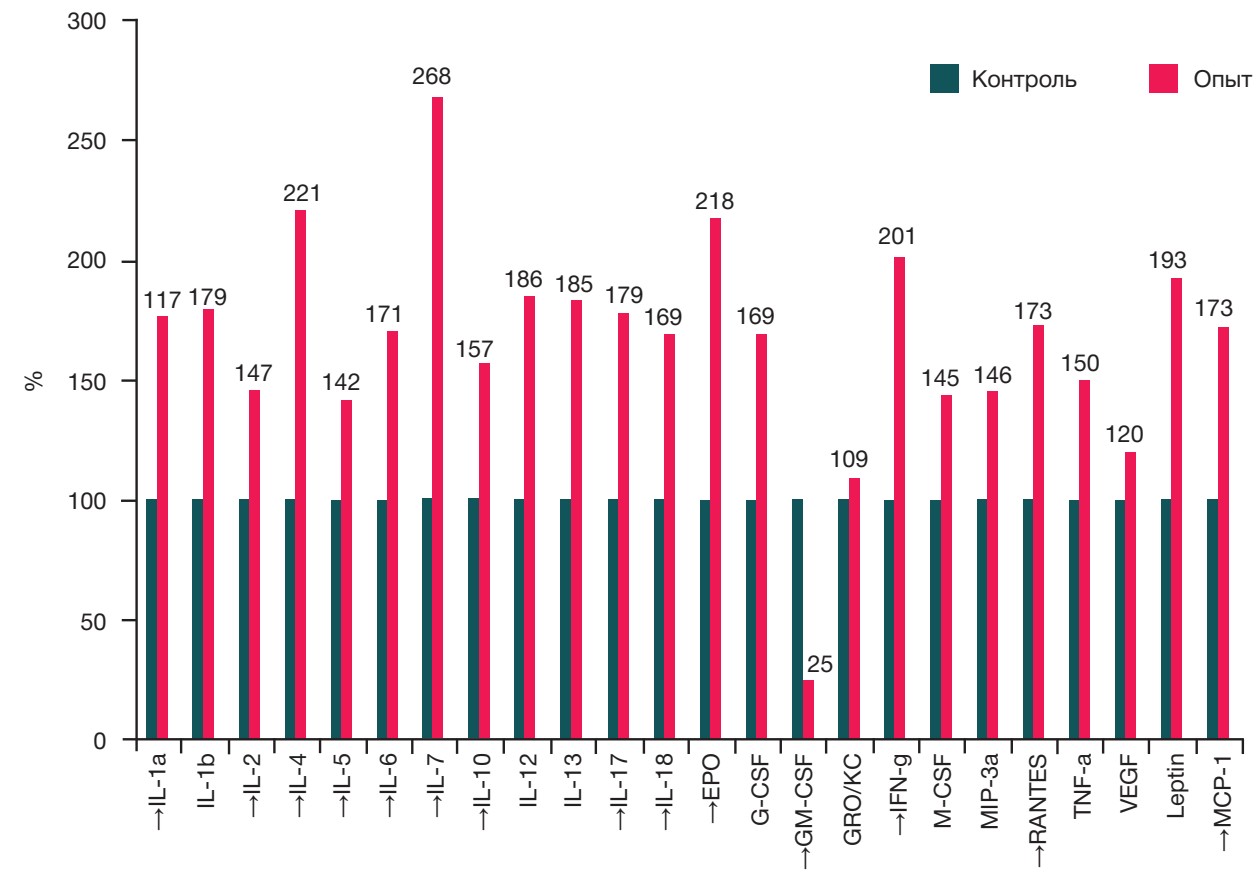

Рис. 3. Изменение содержания цитокинов в сыворотке крови крыс экспериментальной группы по сравнению с крысами контрольной группы через 7 суток после иммунизации. Содержание цитокинов в крови животных контрольной группы были приняты за 100 \%. Достоверные различия показаны стрелками

фоне падения уровня продукции GM-CSF, можно рассматривать в качестве каскада, индуцированного при участии IL-2.

Для ЭАЭ у крыс в отличие от РС у человека не характерна продукция проапоптотических факторов, прежде всего TNF- $\alpha$, несмотря на подъем уровня синтеза его классических индукторов - цитокинов IL12, IL-18 и IFN- $\gamma$ [14]. Таким образом, рост содержания TNF- $\alpha$ при PC следует рассматривать скорее в качестве результата, а не причины поражения миелиновых оболочек. В то же время TNF- $\alpha$ может вносить существенный вклад в поражение астроцитов и нейронов на поздних стадиях развития РС.

В соответствии с описанной в работе [10] закономерностью, наблюдавшиеся нами подъем и спад продукции IFN- $\gamma$ и RANTES (CCL-5) у крыс с ЭАЭ, происходившие синхронно, следует рассматривать как процессы, характерные и для РС у человека.

На ранней стадии развития ЭАЭ у крыс нами не было выявлено изменение уровня накопления в крови GRO/KC (CXCL1), ответственного за инфильтрацию лимфоцитов в ЦНС, что отличает модель от течения РС у человека (по данным [10]).

Для ЭАЭ у крыс и РС у человека в равной мере характерна гиперпродукция IL-17, которая может способствовать накоплению специфических лимфоцитов в ЦНС и активации у них цитотоксических функций.

Несмотря на выраженную гиперпродукцию IL-1b, для PC у человека характерно отсутствие участия в патогенетических реакциях нейтрофилов и факторов их таксиса и активации. В случае с моделью наблюдали похожую реакцию системы нейтрофилов. Фактор пролиферации предшественников нейтрофилов M-CSF не изменял своего содержания в процессе моделирования. То же наблюдали для MIP-3a (CCL20) - фактора защиты слизистых от бактериальной инфекции и лептина, отвечающего за повышение температуры при инфекции.

Гиперпродукцию IL-4 и IL-10 при ЭАЭ у крыс, особенно на фоне повышенного содержания IL-5, IL-13 и GM-CSF, следует рассматривать в качестве фактора, стимулирующего пролиферацию В-лимфоцитов. Теоретически этот набор факторов может способствовать появлению олигоклональных антител, однако такой факт до настоящего времени никем не был описан.

Отвечая на вопрос о локализации очага пролиферации миелин-специфичных лимфоцитов - внутри или вне ЦНС, необходимо отметить, что выбранная модель демонстрирует принципиальную возможность запуска этой реакции вне ЦНС. Однако динамика развития заболевания при ЭАЭ у крыс и РС у человека значительно различается. Нельзя исключать, что при развитии РС у человека первым событием является инфильтрация в ЦНС лимфоцитов, не прошедших клональную экспансию, которые затем подвергаются селекции в условиях избытка миелина. На аномальное поведение лимфоцитов в модели может влиять их первоначальная клонально-неспецифическая гиперпролиферация под действием системного или местного избытка лимфопролиферативных факторов и/или возникновение градиента лимфотактических факторов, исходящего из ЦНС. Альтернативой может быть инициация аномально быстрой деградации миелина в ЦНС, приводящая к массовому выходу продуктов его распада в системную циркуляцию. В этом случае модель является наиболее адекватной ранним стадиям РС у человека.

\section{ВЫВОДЫ}

Данные о динамике содержания цитокинов при ЭАЭ у крыс, полученные с помощью мультиплексного цитокинового теста, показали, что с точки зрения цитокинового профиля модель соответствует течению рассеянного склероза у человека в части динамики содержания системных лимфопролиферативных и гемопоэтических факторов: IL-1b, IL-2, IL-4, IL-5, IL-6 и IL-7. В отношении факторов таксиса лимфоцитов, моноцитов и других клеток иммунной системы модель удовлетворительно имитирует поведение IL-17, RANTES (CCL-5) и MCP-1 (CCL-2), но отличается по поведению GRO/KC (CXCL1). Применительно к факторам, влияющим на цитотоксические и апоптотические реакции, модель схожа с течением РС у человека по таким ключевым факторам, как IFN $\gamma$, IL-6 и IL-17, но не по TNF $\alpha$. 
1. Noonan CW, Kathman SJ, White MC. Prevalence estimates for MS in the United States and evidence of an increasing trend for women. Neurology. 2002 Jan 8; 58 (1): 136-8.

2. Lucchinetti C, Brück W, Parisi J, Scheithauer B, Rodriguez M, Lassmann $\mathrm{H}$. Heterogeneity of multiple sclerosis lesions: implications for the pathogenesis of demyelination. Ann Neurol. 2000 Jun; 47 (6): 707-17.

3. McDonald WI, Compston A, Edan G, Goodkin D, Hartung HP, Lublin FD et al. Recommended diagnostic criteria for multiple sclerosis: guidelines from the International Panel on the diagnosis of multiple sclerosis. Ann Neurol. 2001 Jul; 50 (1): 121-7.

4. Kremenchutzky M, Cottrell D, Rice G, Hader W, Baskerville J, Koopman $\mathrm{W}$ et al. The natural history of multiple sclerosis: a geographically based study. 7. Progressive-relapsing and relapsing-progressive multiple sclerosis: are-evaluation. Brain. 1999 Oct; 122 (Pt 10): 1941-50.

5. Confavreux C, Vukusic S, Moreau T, Adeleine P. Relapses and progression of disability in multiple sclerosis. $\mathrm{N}$ Engl J Med. 2000 Nov 16; 343 (20): 1430-8. DOI: 10.1056/ NEJM200011163432001.

6. Weinshenker BG, Bass B, Rice GP, Noseworthy J, Carriere W, Baskerville $\mathrm{J}$ et al. The natural history of multiple sclerosis: a geographically based study. I. Clinical course and disability. Brain. 1989 Feb; 112 (Pt 1): 133-46.

7. Frischer JM, Bramow S, Dal-Bianco A, Lucchinetti CF, Rauschka $\mathrm{H}$, Schmidbauer $\mathrm{M}$ et al. The relation between inflammation and neurodegeneration in multiple sclerosis brains. Brain. 2009 May; 132 (Pt 5): 1175-89. DOI: 10.1093/brain/ awp070.

\section{References}

1. Noonan CW, Kathman SJ, White MC. Prevalence estimates for MS in the United States and evidence of an increasing trend for women. Neurology. 2002 Jan 8; 58 (1): 136-8.

2. Lucchinetti C, Brück W, Parisi J, Scheithauer B, Rodriguez M, Lassmann $\mathrm{H}$. Heterogeneity of multiple sclerosis lesions: implications for the pathogenesis of demyelination. Ann Neurol. 2000 Jun; 47 (6): 707-17.

3. McDonald WI, Compston A, Edan G, Goodkin D, Hartung HP, Lublin FD et al. Recommended diagnostic criteria for multiple sclerosis: guidelines from the International Panel on the diagnosis of multiple sclerosis. Ann Neurol. $2001 \mathrm{Jul} ; 50$ (1): 121-7.

4. Kremenchutzky M, Cottrell D, Rice G, Hader W, Baskerville J, Koopman $\mathrm{W}$ et al. The natural history of multiple sclerosis: a geographically based study. 7. Progressive-relapsing and relapsing-progressive multiple sclerosis: are-evaluation. Brain. 1999 Oct; 122 (Pt 10): 1941-50.

5. Confavreux C, Vukusic S, Moreau T, Adeleine P. Relapses and progression of disability in multiple sclerosis. N Engl J Med. 2000 Nov 16; 343 (20): 1430-8. DOI: 10.1056/ NEJM200011163432001.

6. Weinshenker BG, Bass B, Rice GP, Noseworthy J, Carriere W, Baskerville $J$ et al. The natural history of multiple sclerosis: a geographically based study. I. Clinical course and disability. Brain. 1989 Feb; 112 (Pt 1): 133-46.

7. Frischer JM, Bramow S, Dal-Bianco A, Lucchinetti CF, Rauschka $\mathrm{H}$, Schmidbauer $\mathrm{M}$ et al. The relation between inflammation and neurodegeneration in multiple sclerosis brains. Brain. 2009 May; 132 (Pt 5): 1175-89. DOI: 10.1093/brain/ awp070.
8. Mensah-Brown EP, Shahin A, Garey LJ, Lukic ML. Neuroglial response after induction of experimental allergic encephalomyelitis insusceptible and resistant rat strains. Cell Immunol. 2005 Feb; 233 (2): 140-7. DOI: 10.1016/j.cellimm.2005.04.023.

9. Contarini G, Giusti P, Skaper SD. Active Induction of Experimental Autoimmune Encephalomyelitis in C57BL/6 Mice. Methods Mol Biol. 2018; 1727: 353-60. DOI: 10.1007/978-1-4939-75716_26.

10. Khaibullin T, Ivanova V, Martynova E, Cherepnev G, Khabirov F, Granatov $E$ et al. Elevated Levels of Proinflammatory Cytokines in Cerebrospinal Fluid of Multiple Sclerosis Patients. Front Immunol. 2017 May 18; 8: 531. DOI: 10.3389/fimmu.2017.00531.

11. Albanesi C, Scarponi C, Cavani A, Federici M, Nasorri F, Girolomoni G. Interleukin-17 is produced by both Th1 and Th2 lymphocytes, and modulates interferon-gamma- and interleukin4-induced activation of human keratinocytes. $J$ Invest Dermatol. 2000; 115(1): 81-7.

12. Beeton C, Garcia A, Chandy KG. Induction and clinical scoring of chronic-relapsing experimental autoimmune encephalomyelitis. J Vis Exp. 2007; (5): 224. DOI: 10.3791/224.

13. Повещенко А. Ф., Казаков О. В., Орлов Н. Б., Повещенко О.В., Ким И. И., Бондаренко Н. А. и др. Цитокины сыворотки крови как маркеры онкогенеза и эффективности терапии при экспериментальной опухоли молочной железы крыс Wistar. Фундаментальные исследования. 2015. 1 (4. 8): 1664-70.

14. Hamblin AS. Lymphokines and interleukins. Immunology. 1988; 64 (Suppl 1): 39-41.

8. Mensah-Brown EP, Shahin A, Garey LJ, Lukic ML. Neuroglial response after induction of experimental allergic encephalomyelitis insusceptible and resistant rat strains. Cell Immunol. 2005 Feb; 233 (2): 140-7. DOI: 10.1016/j.cellimm.2005.04.023.

9. Contarini G, Giusti P, Skaper SD. Active Induction of Experimental Autoimmune Encephalomyelitis in C57BL/6 Mice. Methods Mol Biol. 2018; 1727: 353-60. DOI: 10.1007/978-1-4939-75716_26.

10. Khaibullin T, Ivanova V, Martynova E, Cherepnev G, Khabirov F, Granatov E et al. Elevated Levels of Proinflammatory Cytokines in Cerebrospinal Fluid of Multiple Sclerosis Patients. Front Immunol. 2017 May 18; 8: 531. DOI: 10.3389/fimmu.2017.00531.

11. Albanesi C, Scarponi C, Cavani A, Federici M, Nasorri F, Girolomoni G. Interleukin-17 is produced by both Th1 and Th2 lymphocytes, and modulates interferon-gamma- and interleukin4-induced activation of human keratinocytes. J Invest Dermatol. 2000; 115(1): 81-7.

12. Beeton C, Garcia A, Chandy KG. Induction and clinical scoring of chronic-relapsing experimental autoimmune encephalomyelitis. J Vis Exp. 2007; (5): 224. DOI: 10.3791/224.

13. Poveschenko AF, Kazakov OV, Orlov NB, Poveschenko OV, Kim II, Bondarenko NA et al. Serum cytokines of Wistar rats markers of carcinogenesisand effectiveness of cancer therapy. Fundamental research. 2015; 1 (Pt 8): 1664-70. Russian.

14. Hamblin AS. Lymphokines and interleukins. Immunology. 1988; 64 (Suppl 1): 39-41. 